\title{
Eyeing Ideological Construction: Interrogating Women and Men Representations in the Language of Online Advertisements
}

\author{
Astelia Mihayo, Universitas Airlangga
}

\begin{abstract}
This paper examines the language of online advertisements in telecom companies in Tanzania. The study in particular, interrogates the way language mediates cultural ideologies and media in relation to the status and position of women in the society. A total of 15 selected online advertisements from Tigo Tanzania,Vodacom Tanzania, and Airtel Tanzania Limited telecom were analysed through Content Analysis Method. Through the analysis and interpretation of online advertisements, it can be argued that online advertisements of the companies are ideologically representative of the existing power relations that affects the women subgroup in the Tanzanian society. The language of the online advertisements is ascribed with the stereotyping and an appendage women's roles compared to their counterparts men to appeal men consumers and those with male-defined interests. However, with increasing efforts to impart awareness on equality and women's right today, some advertisements ascribe women with positive roles that in the same way appeal taste of the consumers of the services and products of the companies.
\end{abstract}

Keywords: cultural studies; ideology; online advertisement; women and power relations

\section{Introduction}

The representation of women and men in various forms of media is often characterized by contested debates among scholars and professionals across cultures in different spaces. From printed media, radio, television to internet media, women are neither represented equally with men. The manner of their representation in media reflects their role and status in the society. Whereas, the representation of women and men in printed media, television, and radio has attracted researchers and media experts globally, the representation of women and men in internet is yet to receive such attention. The paper owes to interrogate women and men's representation in online advertisements in the Tanzanian context.

The ever-increasing use of internet spaces to mediate services, products, and consumers is celebrated by both business partners and the consumers. However, the internet media has been impugned to significantly influence behavior, attitudes, and the way one perceives the world and others. According to Shartiely (2005), technological inventions of the modern world have equally been playing in constant supplying of information that traditionally were through social institution like family, church, schools, and others like the political and economic institutions. In addition, Shartiely (2005) added that the social institutions supplied information that influence and mold the behavior and attitudes to understand the world and others.

So far, internet media spaces are platforms of informing, educating, entertaining, and more importantly do influence and shape attitudes and behavior of the social group in their cultural milieu (Solomon, 2006; Govender, 2015). For Solomon (2006) and Hajimohammadi (2011), what we often see, hear, or read in media is a selection and reflection of particular priorities, views within certain ideological constructs. Thus, such a selection and its presentation in specific media output, produce and reproduce certain assumptions, meaning, perception, and of course ideologies on how to understand social groups in place. Solomon (2006) noticed that such assumptions, meaning, perception, and ideologies are often inscribed in the roles and status of different social groups.

Consequently, internet media provides an avenue to understand not only culture but also ideological structures on power relations, stereotypes, and meanings of a particular cultural group. 
According to Hajimohammadi (2011), mediated representations of certain cultural groups are often located within the certain ideological framework that reflect the existing power relations, stereotypes, and structures of meaning. In so doing ideology not only establishes discourses but also reproduces maps of meaning, assumptions, beliefs, and attitudes that in one way or another succumb to understanding of the cultural groups within sets of cultural practice.

Advertising as one of the internet media genres has been a useful popular medium that inter alia represents, carries, and pervade such ideological discourses of given cultural groups. Hajimohammadi (ibid) put it opulently that in addition to information regarding services and products that advertisements are primarily concerned about, they secondarily establish ideological discourses about society and power relations. "Gender relations" is one of those secondary discourses that advertisements construct. It is in this light, this paper interrogates the language of online advertisement, particularly in Tanzanian telecom companies. This paper particularly interrogates the way language mediates cultural ideologies and media in relation to the status and position of women in the society.

According to Shartiely (2005), Furnham and Paltzer (2010), and Hajimohammadi (2011), in today's modern world of trade competition, online advertisements have not only become a powerful force in media for mediating business of services and goods, but also significant in enhancing the social ideologies that they selectively endorse to the society. Stanton (1981) on the other hand, saw that even for business purposes, advertisers selectively use cultural marketing strategies drawn from dominant social ideologies to persuade people to purchase, products or change their attitudes towards goods or existing brands to new ones. Building on what Louis Althusser's contends about the theory of ideology, Eagleton (1983) argued that dominant ideologies that are ascribed in representations relocate of daily social practices, meanings with regard to gender relations for the outputs and for this case mediated representation of women and men in online advertisements.

Fauconnier (1979) claimed that most advertisements involve use of verbal and non-verbal image of a woman because of the close relationship which exists between advertising, the consumer goods industry and economic role of women as consumer. For Morna (2001), such sexist coverage of a woman and a man has long been used as a justification for increasing sales. Morna (ibid) continued to argue that the male dominated media-marketing departments have also tended to imagine their audiences as being largely male or at least having male defined interests. In so saying women and men representations in advertisements is of imbalance and ideologically biased with men being advantaged to manipulate their dominant ideologies and so pervading discourses of meanings to the society. Consequently, advertising as a cultural avenue and discourse on the other hand, "different subjectivities struggle to impose or challenge, to confirm, negotiate or displace definitions and identities" (Gledhill, 1988). For Fauconnier (1979), Barker (2004), and Hajimohammadi (2011), such women and men representations in media, online advertisements in particular, are linked with collective meanings, power relations, status hierarchies, resistance, alliances or conflicts that may exist in the public sphere.

It is in this light, this study examines on how the language of online advertisement in telecom companies Tanzania, in particular, mediates cultural ideologies and media in relation to the status of women and men in the society. The study deployed Content Analysis Method to examine the language of online advertisement in 3 telecom companies in Tanzania, namely Vodacom, Airtel, and TIGO. The textual analysis concentrates on visual and linguistic representation of women in commercial advertisement and how they construct the intelligible meanings to consumers of such advertisement and hence reflect the ideological construct of the community. The analysis relocates the women representation in the Tanzanian cultural setting as well as in the existing cultural mythologies and ideologies and their influence in setting the dominant discourse. 


\subsection{Portrayal of motherhood in advertisements}

In many African societies, women are conceived to be in full when they bear children and become responsible in the whole process of nurturing. Akujobi (2011) clarified that women enter motherhood institution and become defined by the children they bear. Of this view, women become ideological repressed and stigmatized at onset of their existence unlike men in the society. This is observed in Gorbatai and Nelson (2015) as she puts, "according to traditional gender stereotype, women should have a feminine personality, they should be passive and look beautiful for men, and they should embody a wife and mother role only, and be able to take care of their families, such as cooking and rearing children".

The selected advertisement in Figure 1 below echoes such ideological constructions as women are ascribed with respect to children they are attached. They are mothers of children and they are responsible in the nurturing process of the children they are attached to. The woman in the advertisementis pictured with her child in many times and the man would join to support the role of nurturing,but essentially, nurturing is for mothers. As in Figure 1, the verbal message, namely "Hakunapendo la dhatikama la mama", which means "there is no real love like that of the mother,"stresses on how mothers attachments to children define women culturally. For Fowles (1996, in Gorbatai \& Nelson, 2015), the role of such portrayal of women is to create a connection between the product and social and cultural components as well as the norm of everyday life. Of a particular note, women would have multiplied roles of nurturing even their husbands in most African societies and of course, inTanzanian societies, too.

Figure 1: Portrayal of motherhood in the advertisement

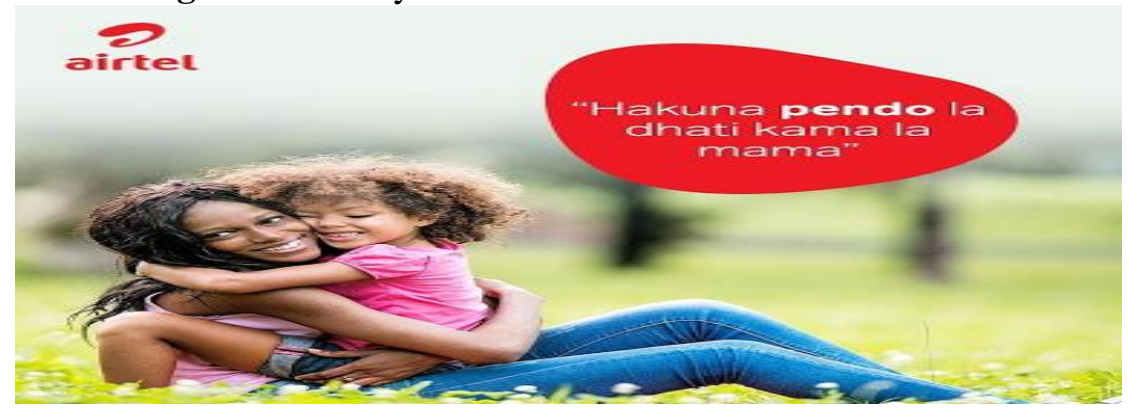

\subsection{Portrayal of women in household's tasks}

Tanzania, like many other African countries, prescribes women's and men's roles according to sex. Whereas women are presumed to perform domestic chores such as cooking, cleaning, and child care, men are presumed to be heads of the households. Blackstone (2003) asserted that:

"The traditional view of the feminine gender role prescribes that women should behave in ways that are nurturing. One way that a woman might engage in the traditional feminine gender roles would be to nurture the family by working fulltime, within the home rather than taking employment outside of home. Men, on the other hand are presumed by traditional view of gender roles to be leaders"

In the light of the above view, men are more privileged to work outside home, while women are relegated to household's tasks. The selected advertisement resonances such ideological constructions as women are portrayed with respect to kitchen attachments. Women are portrayed cooking delicious dishes for their children and family as prescribed in traditional gender roles. As verbal messages, such as, "MWANAMKE JIKO" which literally means "a woman is a kitchen," 
reminds women about their traditional roles in the family. Here, the message suggests that cooking is traditionally prescribed for women and not for men. Manju (2014) corroborated with the foregoing claim and stated that, "the early study of women's roles portrayal suggests that the advertisement on women reflects stereotypical role like women taking care of homes, cooking, and not making important decisions". Hence, this advertisement reflects the ideological construction on traditional gender roles in Tanzanian society.

\subsection{Portrayal of women dependence over men}

As pointed out earlier, while the traditional view of gender roles prescribed women to nurture and bound to household's tasks, men took jobs outside the house and considered responsible for taking care of the family financially. Blackstone (2013) argued that, "men are presumed by traditional view of masculinity gender roles to be heads of their households by providing financially for the family and making important decisions." This traditional view on gender roles puts women in dependent situation over men.

The selected advertisement in Figure 2 below reflects such ideology as women are portrayed economically dependent over men. Women are depicted requesting financial support, unlike men are. The image of a hand giving money to the woman, suggests male's domination and authority over female financially. Additionally, the verbal messages, such as, "NITIGOPESA" which means "send me money" represent a woman's voice asking for financial support.

Unlike women, men are portrayed as independent. As in Figure 2, men are depicted holding a tricycle key, smiling with verbal message, for instance "MILIKI BIASHARA YAKO" which means "own your business". This message strongly attracts male's interests and encourages men to work hard and maintain the ownership of properties. On the other hand, the message may represent men's ownership of properties in the society. Such representation of men and women in advertisements are not free from the social ideological set ups and the prevailing cultural mythologies of the dominant cultural group in the media industry as well as in the society.

Figure 2: Portrayal of women as dependent over men.

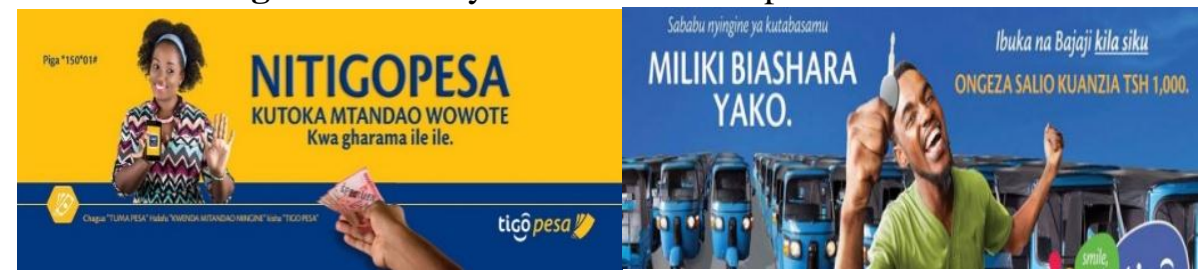

\subsection{Only beautiful and young girls matter}

In Tanzanian setting young, beautiful and attractive women are used in advertisements, promotions, or public appearance to attract consumers. Warren (1978) corroborated with the foregoing claim but he provocatively argued that the use of beautiful and young girls in advertising industry is to reward male consumers, which is already constituted in the social structure.

The selected advertisement echoes such ideology as women are ascribed with beauty. Women are depicted decorating their face. This can be a special way of advertising the program and encouraging women to buy it. As theverbal message, such as, "Hitimucheti cha VETA koziyaurembokinganjanimwakokupitia VSOMO App. Pakua App hiisasa" which means "graduate a certificate of beauty through VSOMO App. Download it now" attracts the readers' interest over the advertised program and suggests that women may use the application to learn about beauty and please others. This is equally with what women like to do in everyday life. 


\subsection{Portrayal of men in advertisement}

In African societies, men and women in most cases are only stereotyped in family relationship - husband and wife. Gorbatai and Nelson (2015) asserted that, "men and women relationship cannot be depicted out of engagement or marriage in Moroccan society". With regards to this claim, men and women can only be depicted in married couple and not otherwise. However, due to the change of lifestyles, men and women are depicted out of family relationship. Kellner (1995) stated that:

"Visual images in advertising attempt to create a relation between the commodity and social or cultural characteristics and qualities. Images do not have only the role of reinforcing the idea of selling a product, but they have also a strong role in selling a "worldview" a lifestyle and value system".

The selected advertisement in Figure 3 below sells modern lifestyles view to the society, such as men are depicted carrying women's handbags. Here, men are likely to be of modern life, because traditionally, men are stereotyped masculine. In Figure 3, proves the depiction through the verbal messages, for instance, "I DARE YOU UWEKE PICHA UKIWA UMEBEBA MKOBA $W A K E$," which suggests that it is not normal for men to carry handbags' of their partners. However, because of modernization, the task belongs to malesis apparently taken as the symbol of love and caring to their partner. Therefore, the advertisement tries to marginalize the traditional roles and set up modernity.

Figure 3: Portrayal of women accompanied by men in advertisement.

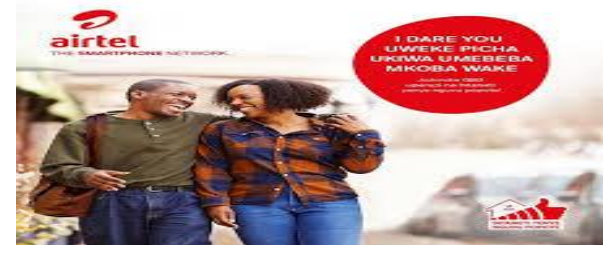

\subsection{Portrayal of women as works in different occupations}

Men's and women's roles in the society have been changing for decades. Traditionally, men should be working outside the home and held jobs including doctor, lawyer, and politician. Women, on the other hand, governed the domestic sphere. If they did work, they worked as secretaries. Consequently, feminist movements worked to deconstruct gender roles and offer alternative vision of gender roles that emphasize equality between men and women (Blackstone, 2013). Morna (2001) and Solomon (2006) corroborated that "the few changes of such mediated representations of women has been due to some women who work in the media industry and some efforts of media organization that fight for equal representation of women in the media."

The selected advertisements depicted women in least roles likely to men. They are portrayed as engineers, doctors, and contractors. As the verbal message, such as "Kwaniniunafikirikaziyauhandisiniyawanaumepeke?" which means "why do you think engineering works is for men only?" challenges the traditional gender stereotypes by rejecting the traditional stereotypes and influences women to engage in paid occupations. As observed and from living experience, these kinds of advertisements are not of interests of consumers as other six categories of the advertisements pointed out earlier. Undoubtedly, it is because of the operating ideologies and cultural mythologies in place that favors men and marginalize women. 


\section{Conclusion}

To sum up, the manner in which the representation of women is done echoes the social status of women in Tanzanian society. As per discussion, the general overview about the representation of women in online advertisements is ideologically representative of the existing power relations that affect the women's subgroups in Tanzanian community. Their images in online advertisements are ascribed with less or stereotyped roles as rewards for male consumers and whoever with male-defined interests as well as sexual objects to fit male'sdesires. The representation of women in online advertisement is not too far from that of newspapers, magazines, and tabloids as it also looks into the ways women are portrayed in traditional gender roles.

However, with increasing efforts to impart awareness on equality and women rights, currently, several online advertisements in telecom companies ascribe women with positive roles that the same way appeal taste of the consumers.

\section{References}

Barker, C. 2004. Cultural studies.

Blackstone, A. M. 2003. Gender roles and society. Human Ecology: An Encyclopedia of Children, Families, Communities, and Environments. Orono: University of Maine, 335-338.

Eagleton, T. 1983. Literary theory: an introduction. London: Basil.

Fauconnier, G. 1979. Media: the image, role, and social conditions of women. Media.

Furnham, A., \& Paltzer, S. 2010. The portrayal of men and women in television advertisements: An updated review of 30 studies published since 2000. Scandinavian Journal of Psychology, 51(3), 216-236.

Gledhill. 1988. Pleasurable negotiations, female spectators: Looking at film and television. New York: Verso.

Gorbatai, A. D., \& Nelson, L. 2015. Gender and the language of advertisements. Academy of Management Proceedings, 5(1), 15785-15785.

Govender, N. 2015. Magazines' representation of women and the influence on identity construction. Dissertation. Durban University of Technology, South Africa.

Hajimohammadi, A. 2011. Critical analysis of women's representation in tv advertisements from a cultural studies perspective. International Journal of Women "s Research, 107-122.

Kellner, D. 1995. Reading images critically. In Dines, G \& Humez (ed.). Gender, Race and Class in Media. A Text Reader. Thousand Oaks, California: SAGE.

Morna, C. \& Mufune, J. n.d. Media on the a - Gender. Audit of the Southern Africa: Declaration on Gender and Development. In DS Media.

Shartiely, E. N. 2005. The portrayal of the Tanzanian woman in television commercials: is she a piece of soap, a house, or gold? Africa \& Asia, 5(5), 108-141.

Solomon, E. 2006. Women's roles in the media: attitudes towards gender issues in six tanzanian newspapers. Master Thesis. University of Tampere: Tampere, Finland.

Stanton, William, J. 1981. Fundamentals of marketing. New York: McGraw-Hill.

Warren, D. 1978. Commercial liberation. Journal of Communication, 28(1), 169-173. 